\title{
Transplantation in children with failed palliation of hypoplastic left heart syndrome: A good solution?
}

\author{
Paul J. Chai, MD
}

\begin{abstract}
From the Department of Surgery, Columbia University Medical Center, Morgan Stanley Children's Hospital of New York-Presbyterian, New York, NY.

Disclosures: Author has nothing to disclose with regard to commercial support.

Received for publication Oct 2, 2015; accepted for publication Oct 5, 2015; available ahead of print Oct 28, 2015. Address for reprints: Paul J. Chai, MD, Department of Surgery, Columbia University Medical Center, Morgan Stanley Children's Hospital of New York-Presbyterian, 3959 Broadway, CHN 275, New York, NY 10032 (E-mail: pjc2164@cumc.columbia.edu).

J Thorac Cardiovasc Surg 2016;151:176

$0022-5223 / \$ 36.00$

Copyright (c) 2016 by The American Association for Thoracic Surgery

http://dx.doi.org/10.1016/j.jtcvs.2015.10.012
\end{abstract}

Transplantation in patients with single-ventricle circulation after initial palliation is typically associated with worse outcomes. Previous studies have shown 1-year survival after transplant for this group to be as low as $70 \% .^{1,2}$ In this issue of The Journal of Thoracic and Cardiovascular Surgery, Alsoufi and colleagues ${ }^{3}$ analyze data from the Pediatric Heart Transplant Study to report outcomes for transplantation in children who previously had undergone palliation for hypoplastic left heart syndrome. The Pediatric Heart Transplant Study database is a multicenter database of currently more than 50 centers that report cardiac transplants in patients younger than 18 years. Alsoufi and colleagues' current study of 253 patients is the largest study to date looking at this specific subset of patients.

Findings in most cases were not surprising, such as the fact that United Network for Organ Sharing status 1 and need for mechanical circulatory support were associated with death before transplant. The 1-, 5-, and 10-year survivals after transplant were $82 \%, 68 \%$, and $59 \%$, respectively. One of the more interesting findings from the study was that transplant after single-ventricle stage (ie, Norwood vs Glenn vs Fontan) palliation did not affect outcome. This finding is in contrast to previous single-center studies, which have demonstrated worse outcomes with heart transplants after the Fontan procedure. ${ }^{4,5}$ One reason for this may be that all patients in this study were younger than 18 years. This may be indicative of the more complex nature of adults with long-standing Fontan physiology and the usually more complicated nature of their cases from a surgical and medical perspective.

The limitations of the article are clearly mentioned by Alsoufi and colleagues ${ }^{3}$ and have to do mainly with the limitations inherent in working with a multi-institutional retrospective registry. There is likely significant sampling error introduced into the study, which is clearly indicated by the fact that "donor cause of death other than anoxic brain injury" was found to be a risk factor for mortality.

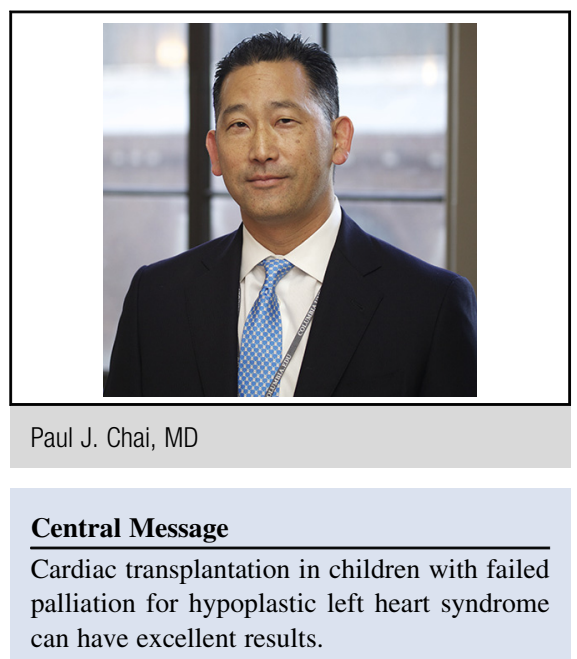

See Article page 167.

See Editorial page 1404 in the December issue.

As Alsoufi and colleagues ${ }^{3}$ mention in their article, a larger report from the same Pediatric Heart Transplant Study database showed that survival after transplant was not affected by cause of donor death, which seems to indicate that sample size played a significant role in the statistical analysis.

This article should serve as an excellent reference for transplantation in children with failed palliation for hypoplastic left heart syndrome. Outcomes continue to improve for children with this condition, and should transplant become a necessity, the results can be encouraging.

\section{References}

1. Everitt MD, Boyle GJ, Schechtman KB, Zheng J, Bullock EA, Kaza AK, et al; Pediatric Heart Transplant Study Investigators. Early survival after heart transplant in young infants is lowest after failed single-ventricle palliation: a multi-institutional study. J Heart Lung Transplant. 2012;31:509-16.

2. Chrisant MR, Naftel DC, Drummond-Webb J, Chinnock R, Canter CE, Boucek MM, et al; Pediatric Heart Transplant Study Group. Fate of infants with hypoplastic left heart syndrome listed for cardiac transplantation: a multicenter study. J Heart Lung Transplant. 2005;24:576-82.

3. Alsoufi B, Mahle WT, Manlhiot C, Deshpande S, Kogon B, McCrindle BW, Kanter K. Outcomes of heart transplantation in children with hypoplastic left heart syndrome previously palliated with the Norwood procedure. J Thorac Cardiovasc Surg. 2016;151:164-75.e2.

4. Davies RR, Sorabella RA, Yang J, Mosca RS, Chen JM, Quaegebeur JM. Outcomes after transplantation for "failed" Fontan: a single-institution experience. J Thorac Cardiovasc Surg. 2012;143:1183-92.e4.

5. Griffiths ER, Kaza AK, Wyler von Ballmoos MC, Loyola H, Valente AM, Blume ED, et al. Evaluating failing Fontans for heart transplantation: predictors of death. Ann Thorac Surg. 2009;88:558-64; discussion 563-4. 